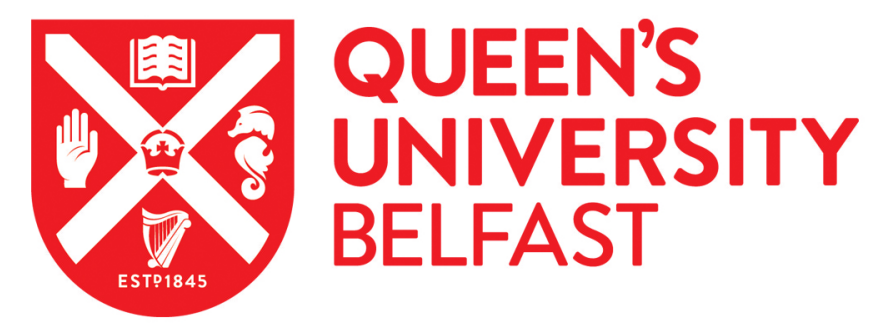

\title{
Very high TAFI antigen levels are associated with a lower risk of hard coronary events the PRIME Study
}

Juhan-Vague, I., Morange, P. E., Evans, A., \& Study, P. R. I. M. E. (2003). Very high TAFI antigen levels are associated with a lower risk of hard coronary events the PRIME Study. Journal of Thrombosis and Haemostasis, 1(10), 2243-2244.

Published in:

Journal of Thrombosis and Haemostasis

Queen's University Belfast - Research Portal:

Link to publication record in Queen's University Belfast Research Portal

\section{General rights}

Copyright for the publications made accessible via the Queen's University Belfast Research Portal is retained by the author(s) and / or other copyright owners and it is a condition of accessing these publications that users recognise and abide by the legal requirements associated with these rights.

Take down policy

The Research Portal is Queen's institutional repository that provides access to Queen's research output. Every effort has been made to ensure that content in the Research Portal does not infringe any person's rights, or applicable UK laws. If you discover content in the Research Portal that you believe breaches copyright or violates any law, please contact openaccess@qub.ac.uk. 

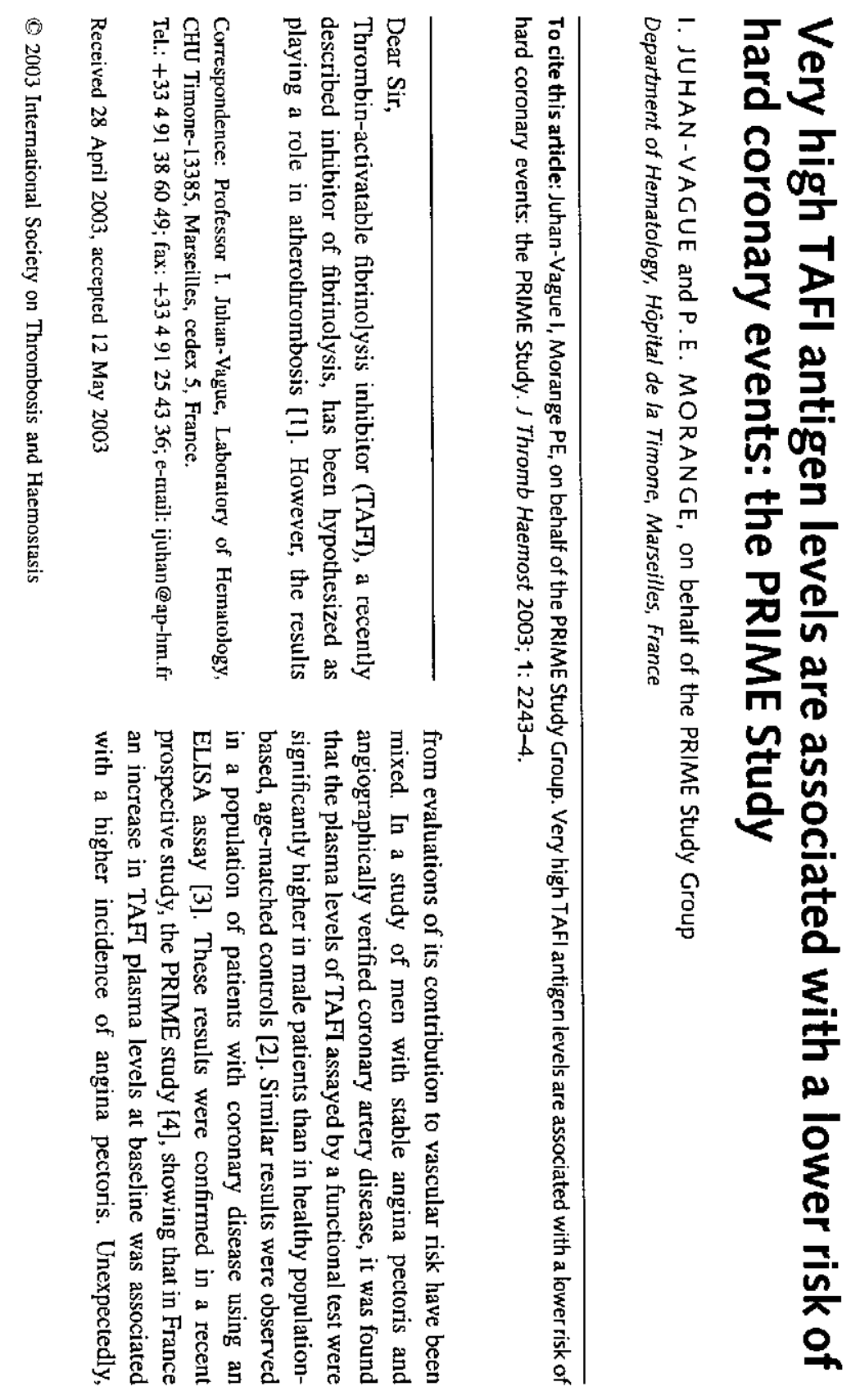

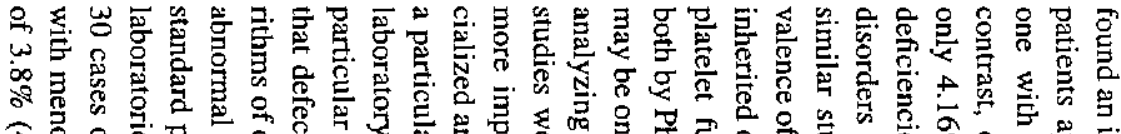

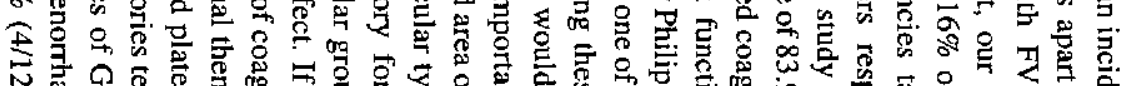
总商.

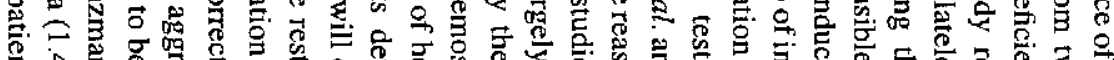

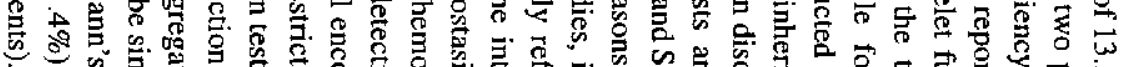

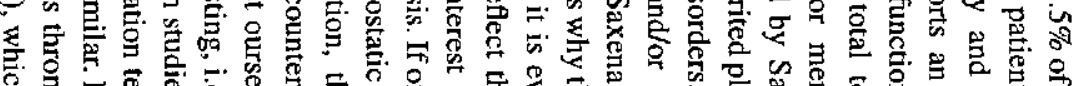

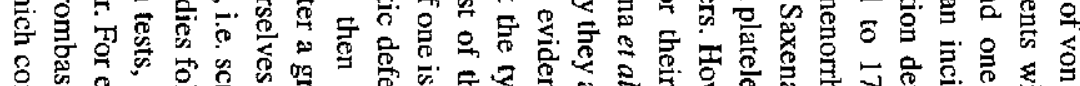

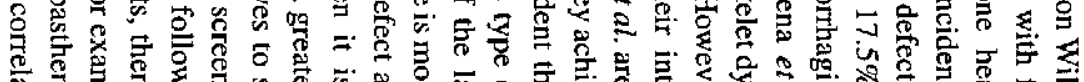

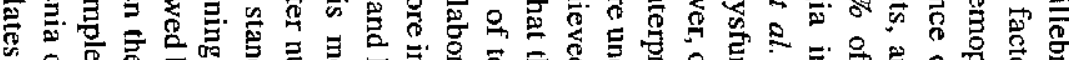

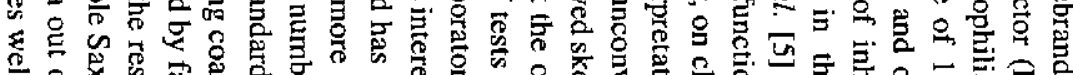

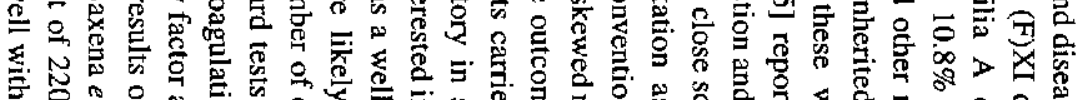

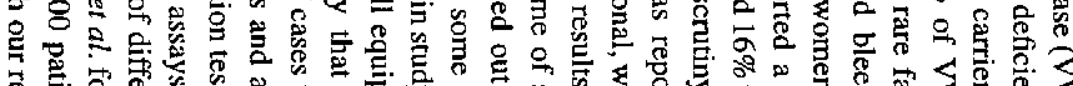

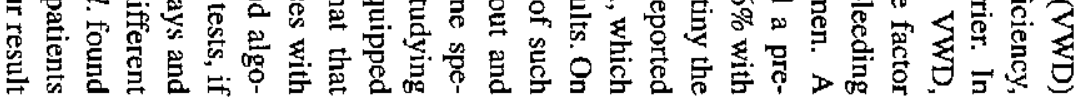
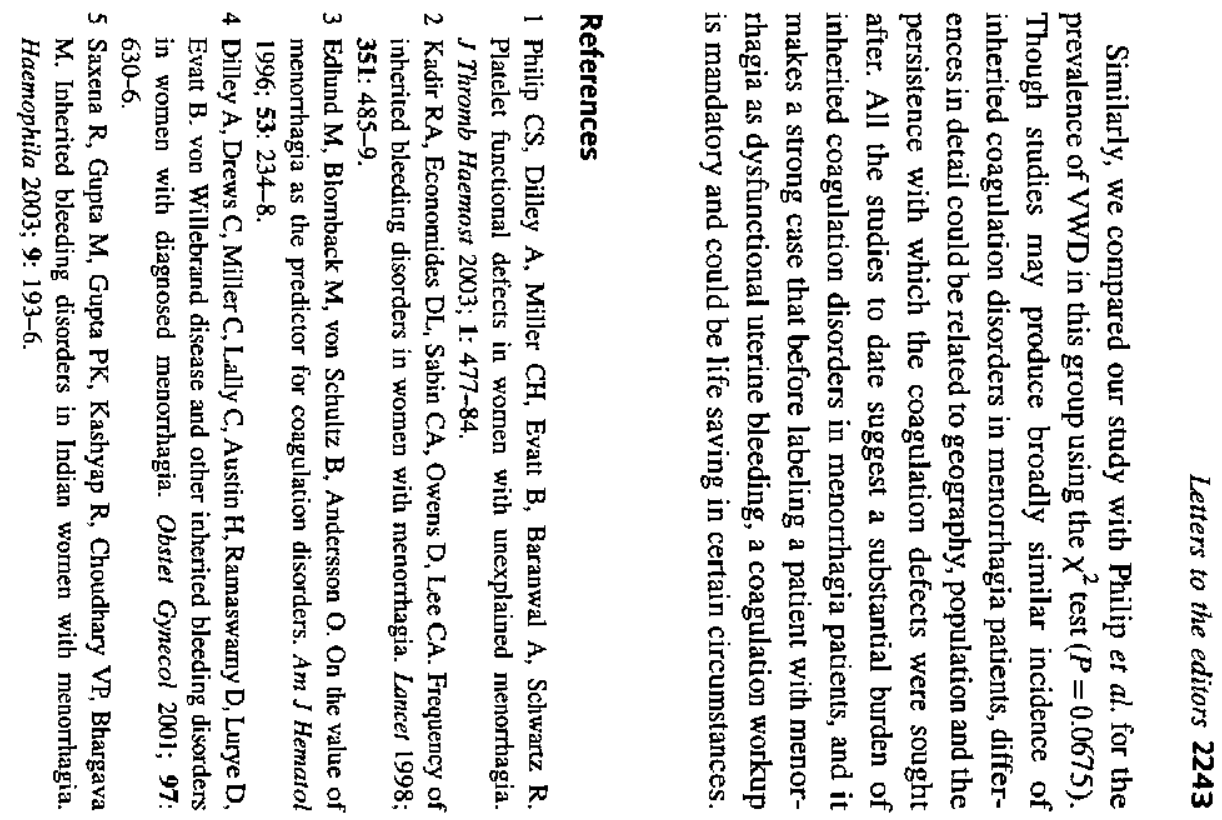


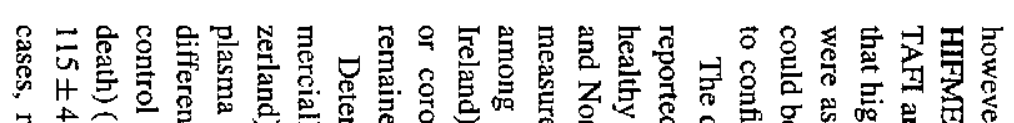

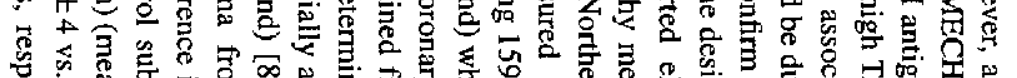

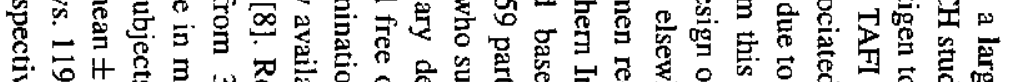

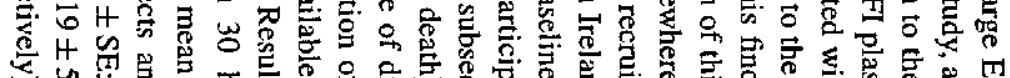

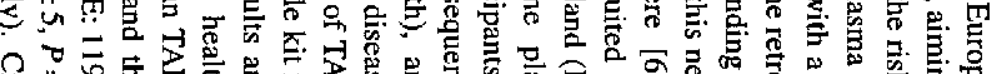

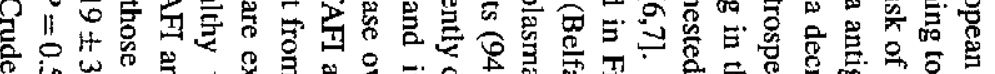

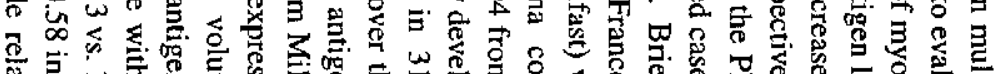

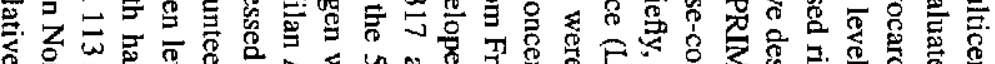

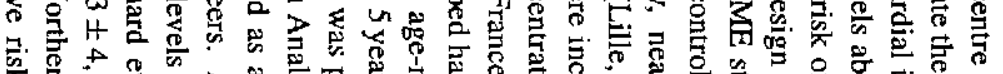

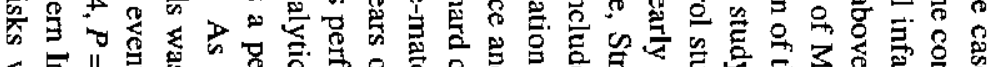

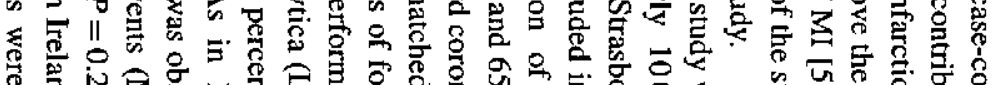

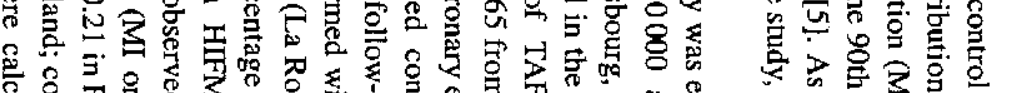

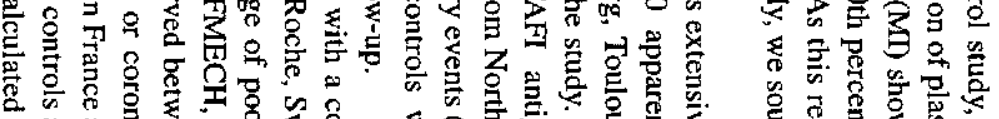

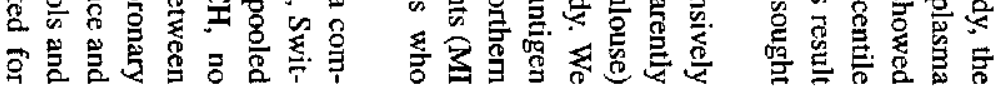

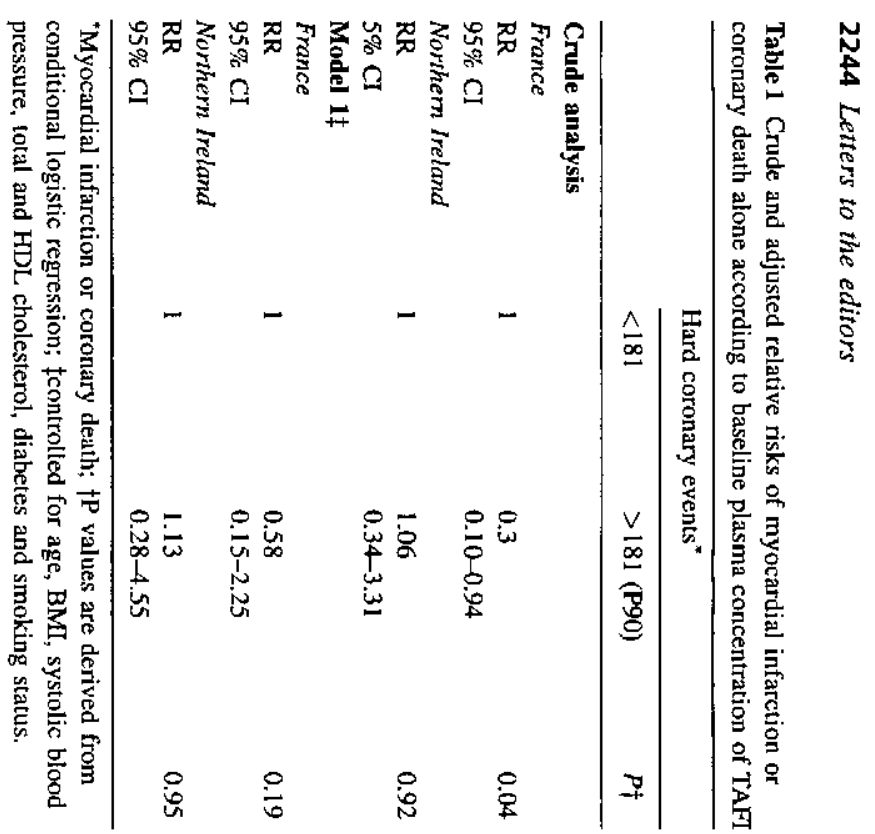

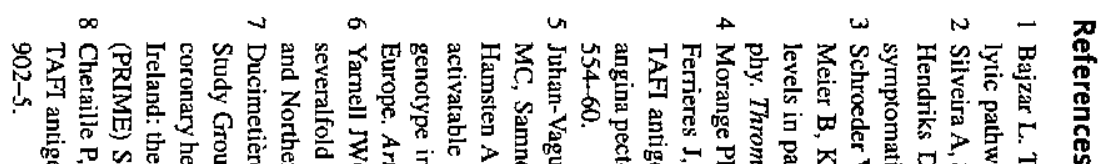

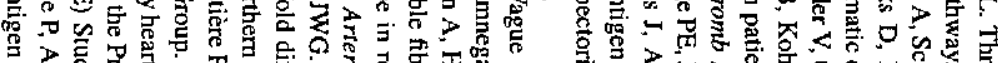

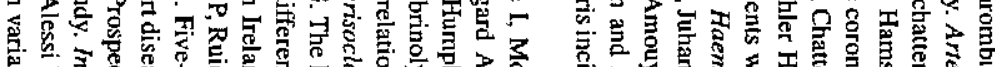

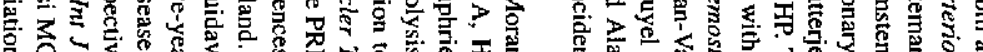

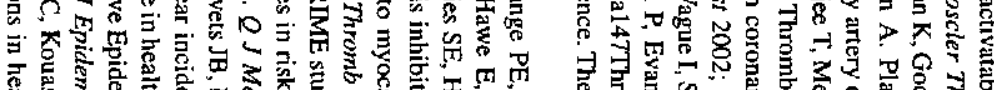

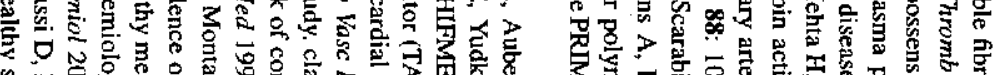

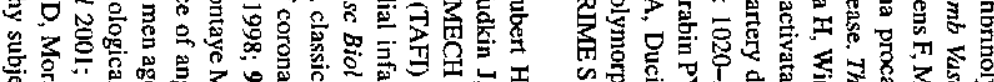

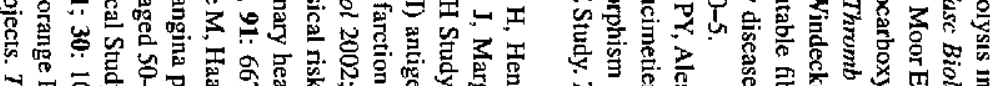

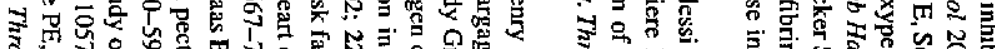

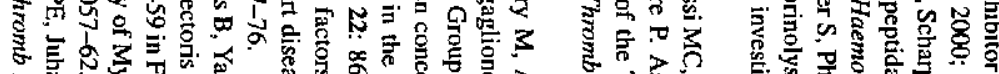

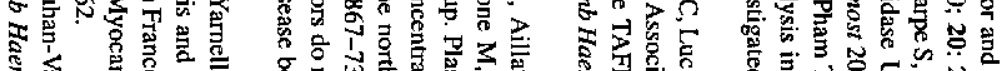

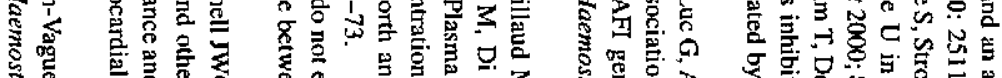
政

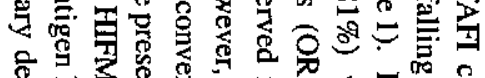
尊

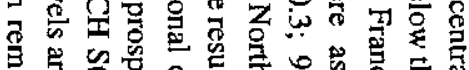

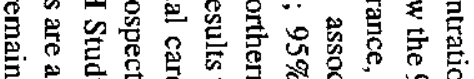

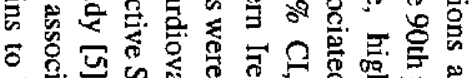

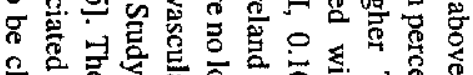

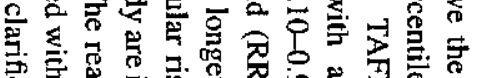

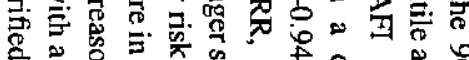

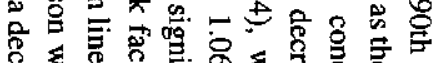

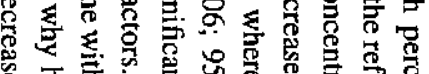

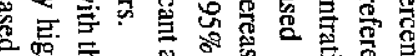

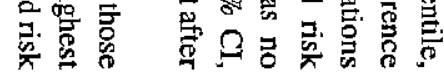

